\title{
Role of Donor Virus-specific Immunity in the Onset of BKV-related Hemorrhagic Cystitis after Hemopoietic Stem Cell Transplantation
}

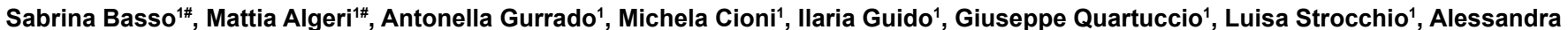
Tolva ${ }^{1}$, Maurizio Zavattoni ${ }^{2}$, Fausto Baldanti ${ }^{2}$, Hans $\mathrm{H} \mathrm{Hirsch}^{3}$, Marco Zecca ${ }^{1}$ and Patrizia Comoli ${ }^{1 *}$

${ }^{1}$ Pediatric Hematology/Oncology, Fondazione IRCCS Policlinico San Matteo, Pavia, Italy

${ }^{2}$ Molecular Virology Unit, Fondazione IRCCS Policlinico San Matteo, Pavia, Italy

${ }^{3}$ Transplantation \& Clinical Virology, and Division of Infection Diagnostics, Department Biomedicine, University of Basel, Basel; Infectious Diseases \& Hospital

Epidemiology, University Hospital Basel, Basel, Switzerland

"SB and MA equally contributed to this work.

\begin{abstract}
BK virus-related hemorrhagic cystitis is one of the major complications of hematopoietic stem cell transplantation. Because an immune reconstitution pattern of disease has been proposed as alternative pathogenetic model, in this study we focused on the link between BKV specific immune responses in the HSCT donor and the development of $\mathrm{HC}$ in paediatric HSCT recipients. We evaluated the frequency of IFN- $\gamma$-producing cells, by means of Elispot assay and flow cytometric measurement of T-cells CD8+/INF $\gamma+$, and specific cytotoxicity, in samples obtained from a cohort of $30 \mathrm{HLA}$-matched unrelated or haploidentical stem cell donors, divided into three groups, according to BKV positivity in urine and development of $\mathrm{HC}$ in recipients. We found that HSCT donors whose recipients developed HC have lower, though not statistically significant, levels of BKV-specific T cells, as compared with donors of recipient with isolated BK-viruria or without viruria. Although we cannot rule out that in some cases also immune reconstitution could play a role in the pathogenesis of $\mathrm{HC}$, our preliminary data suggest that BKV-related $\mathrm{HC}$ may be related to low donor BKV-specific cytotoxic T cell transfer, perhaps coupled with impairment in BKV-specific T cell expansion posttransplant.
\end{abstract}

Keywords: heamtopoietic stem cell transplantation; Haemorrhagic cystitis; Polyomavirus BK; Cellular immunity

\section{Introduction}

Hemorrhagic cystitis (HC) is one of the major complications of hematopoietic stem cell transplantation (HSCT), causing significant morbidity and prolonged hospitalization. Clinical manifestations of HC may vary from microscopic hematuria to severe bladder hemorrhage leading to clot retention and renal failure. The overall incidence of $\mathrm{HC}$ in the HSCT setting has been reported to range between $7 \%$ and $68 \%$ [1-4].

Based on the temporal relationship to donor stem cell engraftment, $\mathrm{HC}$ can be divided into two subtypes: pre-engraftment $\mathrm{HC}$ that occurs during or shortly after high-dose chemotherapy as part of the conditioning regimen and is related to cyclophosphamide (CY) toxicity, and post-engraftment $\mathrm{HC}$ which is mainly attributed to viral infections [5]. Polyomavirus BK (BKV) is the pathogen most frequently associated with post-engraftment $\mathrm{HC}$, although also adenovirus- and cytomegalovirus (CMV) may represent causative agents [6-12].

BKV is a non-encapsulated, double-stranded DNA virus that is highly prevalent in healthy adults, with reported seroprevalence rates reaching $90 \%$ [8]. Transmission is believed to occur via the respiratory tract, especially during early-childhood. After primary infection, which is usually asymptomatic or associated with mild upper respiratory tract symptoms, BKV remains quiescent in renal tubular epithelial cells and the urothelial cell layer, and may reactivate when a natural or iatrogenic state of immunosuppression is imposed [13,14].

Initial studies identified a qualitative association between BKV and HC [7]. After the introduction of PCR techniques, which allowed the determination of BKV DNA load in urine and/or blood samples of HSCT recipients, the association between BK viruria and $\mathrm{HC}$ was strengthened by the demonstration that patients with $\mathrm{HC}$ tend to have higher peak urine viral loads and excrete much larger amounts of BK virus in the urine $[15,16]$. However, about $40-50 \%$ of HSCT patients with persistent viruria do not experience HC. A more recent study suggested that, as for kidney recipients with BKV-associated nephropathy, BK viral load in plasma may be more stringently associated with $\mathrm{HC}$ than BK viruria [17]. However, these data could not be confirmed in a later study [18].

The exact pathogenetic link between BKV and $\mathrm{HC}$ requires further investigation, and it is reasonable to hypothesize that other factors contribute to the development of HC $[4,16]$. Two main theories have been proposed to explain the pathogenesis of BK-related HC. The classical hypothesis is that chemotherapy-induced injury or the cellular regeneration or differentiation after conditioning might exert a direct cytophatic effect on bladder epithelium, making it susceptible to lytic high-level BK infection. The alternative theory is that of an immune reconstitution pattern of disease, in which clinical manifestations are most severe when the immune system is in the process of restoration and viral antigens in the bladder wall are recognized by emerging functioning lymphocytes [19].

The aim of this study was to investigate the latter hypothesis, through assessment of the role played by BKV specific immune response of the HSCT donor in the development of HC.

*Corresponding author: Patrizia Comoli, Pediatric Hematology/Oncology, Fondazione IRCCS Policlinico San Matteo, Viale Golgi 19, Pavia, Italy, Tel: +390382-502716; E-mail: pcomoli@smatteo.pv.it

Received November 25, 2013; Accepted December 21, 2013; Published December 23, 2013

Citation: Basso S, Algeri M, Gurrado A, Cioni M, Guido I, et al. (2013) Role of Donor Virus-specific Immunity in the Onset of BKV-related Hemorrhagic Cystitis after Hemopoietic Stem Cell Transplantation. J Stem Cell Res Ther S6: 007. doi:10.4172/2157-7633.S6-007

Copyright: (C) 2013 Basso S, et al. This is an open-access article distributed unde the terms of the Creative Commons Attribution License, which permits unrestricted use, distribution, and reproduction in any medium, provided the original author and source are credited. 


\section{Patients and Methods}

\section{Patients and specimens}

BKV specific immunity was evaluated in a cohort of 30 HLAmatched unrelated or haploidentical stem cell (SC) donors, divided into three groups, according to BKV positivity in urine and development of $\mathrm{HC}$ in recipients (group 1: BKV DNA+ HSCT recipients with HC: $\mathrm{n}=10$; group 2: BKV DNA+ HSCT recipients without $\mathrm{HC} \mathrm{n}=13$; group 3: BKV DNA- HSCT recipients $n=7)$. The clinical characteristics of the recipients are summarized in Table 1 . This study was performed in accordance with Institutional guidelines, and patients or guardians gave informed consent for the acquisition of additional heparinized blood samples to be employed in this study during routinely performed phlebotomies.

\section{Methods}

Polymerase chain reaction for BKV: BKV DNA analysis on urine and serum samples was performed as previously reported [20].

Harvest and isolation of PBMC: Peripheral blood mononuclear cells (PBMC) were isolated by Ficoll-Hypaque density gradient centrifugation within 24 hours from blood draw and cryopreserved prior to use.

Serology methods: Subjects' serostatus was determined testing 1:400 diluted plasma in an ELISA format for IgG with $50 \mathrm{ng}$ of BK virus-like particles as antigens coated to solid phase purified from VP1 expressing baculo virus infected SF9 cells after lysis and gradient centrifugation. A cut-off of OD492 $\mathrm{nm}>0.110$ after subtraction of nonVLP expressing lysates was considered positive [21,22].

Cellular immunity evaluation: $\mathrm{BKV}$-specific $\mathrm{T}$ cell immunity was evaluated on PBMC collected from the donors at the time of pre-HSCT evaluation and cryopreserved. Cellular immunity was evaluated by measuring (i) IFN- $\gamma$-positive T cells on PBMC by flow cytometry, ii) the frequency of virus-specific IFN- $\gamma$-secreting cells in a ELISPOT assay, and cytotoxicity of BKV-specific cell cultures, using a 51-chromium release assay, on 8-10 day PBMC cultures in the presence of 15-mer peptide pools spanning the entire BKV-VP1 and large T (LT) proteins $(0.5 \mu \mathrm{g} / \mathrm{ml}$ concentration of each single peptide, JPT Peptide Technologies, Berlin, Germany) (Figure 1) [22].

For flow cytometry evaluation, PBMC were cultured for 24 hours in the presence of 15 -mer BKV-VP1 and LT peptide pools $(0.5 \mu \mathrm{g} /$ $\mathrm{ml}$ concentration of each single peptide, JPT Peptide Technologies). $\mathrm{T}$ cells were labeled for $15 \mathrm{~min}$ in the dark at R.T. with fluorescein isothiocyanate (FITC)-conjugated antibody to CD4 or CD8 (BD Biosciences Pharmingen) before fixing and permeabilizing (Fix \& Perm, Caltag Laboratories, Burlingame CA) and then labeling

\begin{tabular}{|l|c|}
\hline Age, median (range) & $\mathbf{1 0} \mathbf{( 2 - 2 4 )}$ \\
\hline Sex, M/F & $15 / 15$ \\
\hline Diagnosis & 21 \\
\hline Malignant & 9 \\
\hline Non-malignant & 18 \\
\hline Type of HSCT donor & 12 \\
\hline HLA-haploidentical & 23 \\
\hline HLA-matched & 10 \\
\hline BK viruria & \\
\hline BKV-related HC & \\
\hline
\end{tabular}

Table 1: Clinical characteristics of the 30 patients enrolled into the study. with phycoerythrin (PE)-conjugated interferon- $\gamma$ (BD Biosciences Pharmingen ) for $40 \mathrm{~min}$ in the dark at R.T. before flow cytometry analysis (FACScalibur, Beckton-Dickinson).

ELISPOT assays were performed according to a previously described method [23]. Briefly, 96-well multiscreen filter plates (MAIPS 4510, Millipore, Bedford, MA) were coated with $100 \mu$ of primary antibody (IFN- $\gamma$, Mabtech, Nacka, Sweden) at $2.5 \mu \mathrm{g} / \mathrm{ml}$, and incubated overnight at $4^{\circ} \mathrm{C}$. Cultured $\mathrm{T}$ cells were seeded in the absence or presence of VP1 and LT peptide mixes $0.5 \mu \mathrm{g} / \mathrm{ml}$ ). After incubation for 24 hours at $37^{\circ} \mathrm{C}, 100 \mu$ of biotinylated secondary antibody (Mabtech, $0.5 \mu \mathrm{g} / \mathrm{ml}$ ) was added, and plates were then processed according to standard procedure. IFN- $\gamma$-producing spots were counted using an Elispot reader (Bioline, Torino, Italy). The number of spots per well was calculated after subtracting the assay background, quantitated as an average of 24 wells containing only sterile complete medium, and specific background (sum of cytokine spots derived from responders alone).

Specific cytotoxic activity was assessed by standard ${ }^{51} \mathrm{Cr}$-release assay, against a panel of targets including autologous phytohemagglutinin (PHA) blasts pulsed for $2 \mathrm{hrs}$ with $2 \mu \mathrm{g} / \mathrm{ml}$ of VP- 1 and LT peptide mix or with $2 \mu \mathrm{g} / \mathrm{ml}$ of control peptide (EBV-LMP2 peptide mix, JPT), and incubated overnight with ${ }^{51} \mathrm{Cr}(100 \mu \mathrm{Ci})$. In brief, PBMC cultured for 8-10 days with VP-1 and LT peptide pools were incubated with target cells at E:T ratios of 20:1, 10:1, 5:1, 2.5:1 [22].

\section{Statistical analysis}

Data were expressed as median and 95\% CI. Comparison of immunological parameters among different patient subgroups was performed by Mann-Whitney test. p-values $<0.05$ were considered statistically significant. Statistical analysis was performed using NCSS System (Cary, NC, USA).

\section{Results}

In this study we focused on the link between BKV specific immune response and the development of HC in paediatric HSCT recipients. Since BKV related HC more frequently occurs in the first 45 days after transplantation, when patient's cellular immunity largely depends on homeostatic expansion of donor's mature lymphocytes transferred

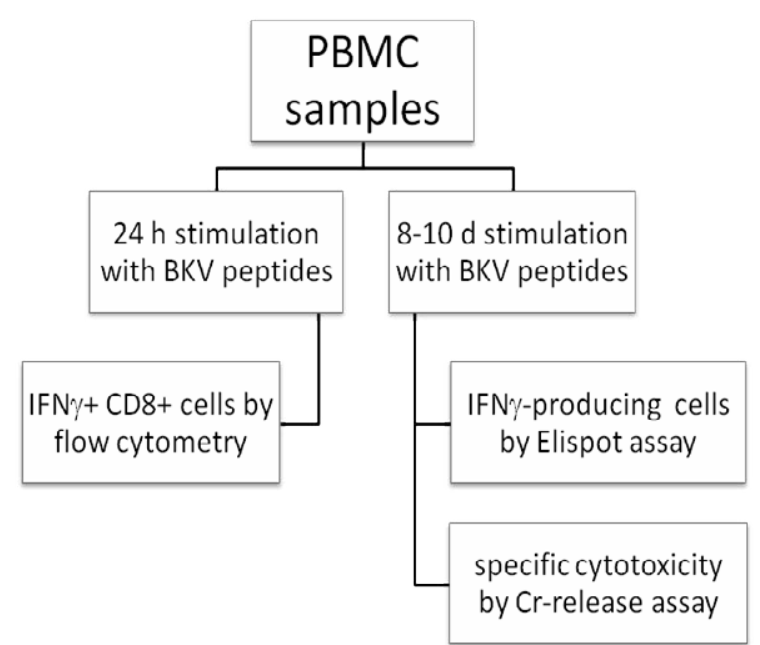

Figure 1: Diagram of the workflow for evaluation of BKV-specific immunity in the HSCT donors. 
within the graft, we decided to investigate the role of BKV specific immune response of the HSCT donor in the development of HC.

In order to assess cellular immunity to $\mathrm{BKV}$, we evaluated the frequency of IFN- $\gamma$-producing cells, by means of Elispot assay and measurement of T-cells CD8+/INF $\gamma+$, and specific cytotoxic capacity by means of standard 51Cr-release assay, in samples obtained from the transplant donor. The results were then analyzed in relation to BKV status of the patient at the time of evaluation.

The donors whose recipients developed BK viruria and presented HC had a lower frequency of BKV-specific CD8+/INF- $\gamma$ cells, compared to the donors of patients who developed viruria without $\mathrm{HC}$ or remained BKV and HC free. Indeed, the number of CD8+/ IFN- $\gamma+$ cells was $1-\log$ lower in donors belonging to group 1 compared with groups 2 and 3 (Figure 2).

We then evaluated numbers of BKV specific IFN- $\gamma$ secreting cells by ELISPOT assay on donor T-cell lines obtained after a 10 day coculture of PBMC with BKV antigens. We found that cultured T cells from donors whose recipients developed HC had lower, though not statistically significant, numbers of IFN- $\gamma$ secreting cells, in comparison to donors belonging to the other two groups [response to VP1, median and 95\% CI in donors of HC patients: 49 (28-107) vs. 121 (29-263) and 65 (28-118) IFN- $\gamma$ spots $/ 10^{5}$ cultured cells in the BKV+ HC-, and in the BKV-negative patient donors, respectively] (Figure 3a).

Since CD8+ T cells and cytotoxic function are thought to be crucial for clearance of virus-infected cells, and are also those responsible for pathology in patients with immune reconstitution syndrome, we then proceeded to evaluate the cytotoxic capacity of BKV-specific T cells present in the donor lines obtained after a 10 day co-culture of PBMC with BKV antigens. Lytic activity against autologous PHA blasts pulsed with BKV-VP1 and LT did not vary significantly in the three groups, although donors of patients with BKV urinary shedding had higher cytotoxic activity than the other groups (Figure $3 b$ ).

We also analyzed humoral donor BKV specific immunity. As shown in Figure 4, although the levels of specific BKV-VLP IgG were not statistically different in the three groups considered, subjects donating to patients that were constantly negative for BK viruria post transplant had higher levels of specific antibodies than donors of HSCT recipients with $\mathrm{HC}$ and/or BK viruria [median BKV-VLP IgG levels in donors of BKV-negative patient: 1.34 vs. 0.70 and 0.50 in the BKV+ HC-, and in the $\mathrm{HC}+$ patient donors, respectively; $\mathrm{p}=\mathrm{ns}]$.

\section{Discussion}

An immune reconstitution pattern of disease has been suggested as alternative hypothesis to explain the pathogenesis of BK-related $\mathrm{HC}$ in the HSCT setting $[4,5,24]$. According to this theory, $\mathrm{HC}$ is the result of an inflammatory process elicited by the recovery of functioning $\mathrm{T}$ lymphocytes after transplantation, engaging viral antigens expressed on the uroepithelium and triggering an immune attack responsible for the extensive mucosal damage and severe bleeding. Support to this theory comes from the observation that $\mathrm{HC}$ is very rare among patients who undergo autologous as compared with allogeneic HSCT, even though similar myeloablative conditioning regimens are used, addressing the alloimmune reactions after allogeneic HSCT as an important contributing factor [19]. Moreover, most cases of postengraftment hemorrhagic cystitis occur in allogeneic HSCT with GVHD, further emphasizing the possible role of the immune system in the pathogenesis of HC [25]. Such kind of immune reconstitution disease has been previously described for JC virus infection in HIV- infected patients treated with antiretroviral combination therapy [26].

Starting from this assumptions, and considering the crucial role that mature $\mathrm{T}$ lymphocytes from the donor could have in the early stages of immune reconstitution [27], we hypothesized that higher number of BKV-specific $\mathrm{T}$ cells in the donor could constitute a risk factor for development of BKV-related HC in the recipient. Our study, however, shows that HSCT donors whose recipients developed HC have lower, though not statistically significant, levels of BKV-specific T cells, as compared with donors of recipient with isolated BK-viruria or without viruria. Indeed, we found that donors whose recipients developed BK viruria and $\mathrm{HC}$ had a lower frequency of BKV-specific CD8+/INF- $\gamma$ cells compared to the donors of patients who persisted BKV-negative or developed viruria but did not exhibit HC, and lower numbers of BKV specific IFN- $\gamma$ secreting cells in ELISPOT assays, compared with donors belonging to the other two groups. Cytotoxic functions, which are crucial for the clearance of virus-infected cells, measured as lytic activity against autologous PHA blasts pulsed with BKV-VP1 and LT, seemed to be similar in all donors' $T$ cell lines, even if this activity was greater in the second group. These data suggest that HSCT donors whose recipients develop HC have lower frequencies of virus-specific CD8+ $\mathrm{T}$ cells that, although numerically scarce, maintain a potential efficient activity. Regarding helper $\mathrm{T}$ cell functions, no significant difference was observed among the different groups, indicating that cytotoxic $\mathrm{T}$ cell rather than helper $\mathrm{T}$ cell function may have a crucial role in controlling BKV infection after HSCT. On the basis of our data, we feel that the hypothesis that $\mathrm{HC}$ is a consequence of an excessive immune reconstitution seems unlikely. Further evidence against the immune reconstitution hypothesis comes from the observation that post-engraftment hemorrhagic cystitis has occurred in patients with very low lymphocyte counts $(<100$ cells $/ \mathrm{ml})$ and in patients receiving high-dose steroids [17] and is more frequent in recipients of haploidentical and cord blood transplants, which are characterized by greater cellular immune incompetence after HSCT [28].

The crucial role of $\mathrm{T}$ cell immunity in the control of BK infection has been previously demonstrated in kidney transplant recipients,

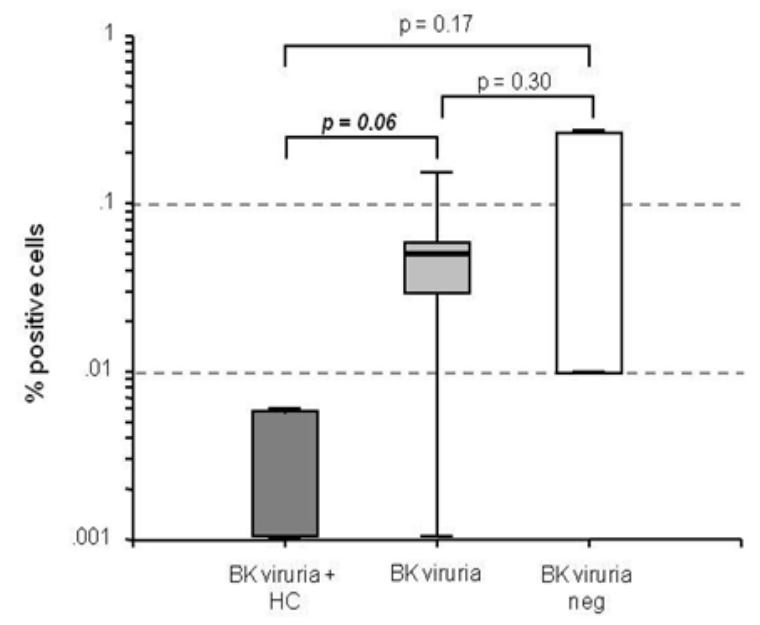

Figure 2: Frequency of BKV-specific CD8+/IFNg+ cells after 24h stimulation with VP1 and T peptides. Percentage of BKV-specific CD8+/IFNg+ cells is represented on a logarithmic scale. All $P$ values are reported those between 0.05 and 0.1 are marked in italics. Evaluated groups: group 1: donors whose recipients developed HC; group 2: donors whose recipients showed BK viruria; group 3: donors whose recipients without BK viruria. 
A
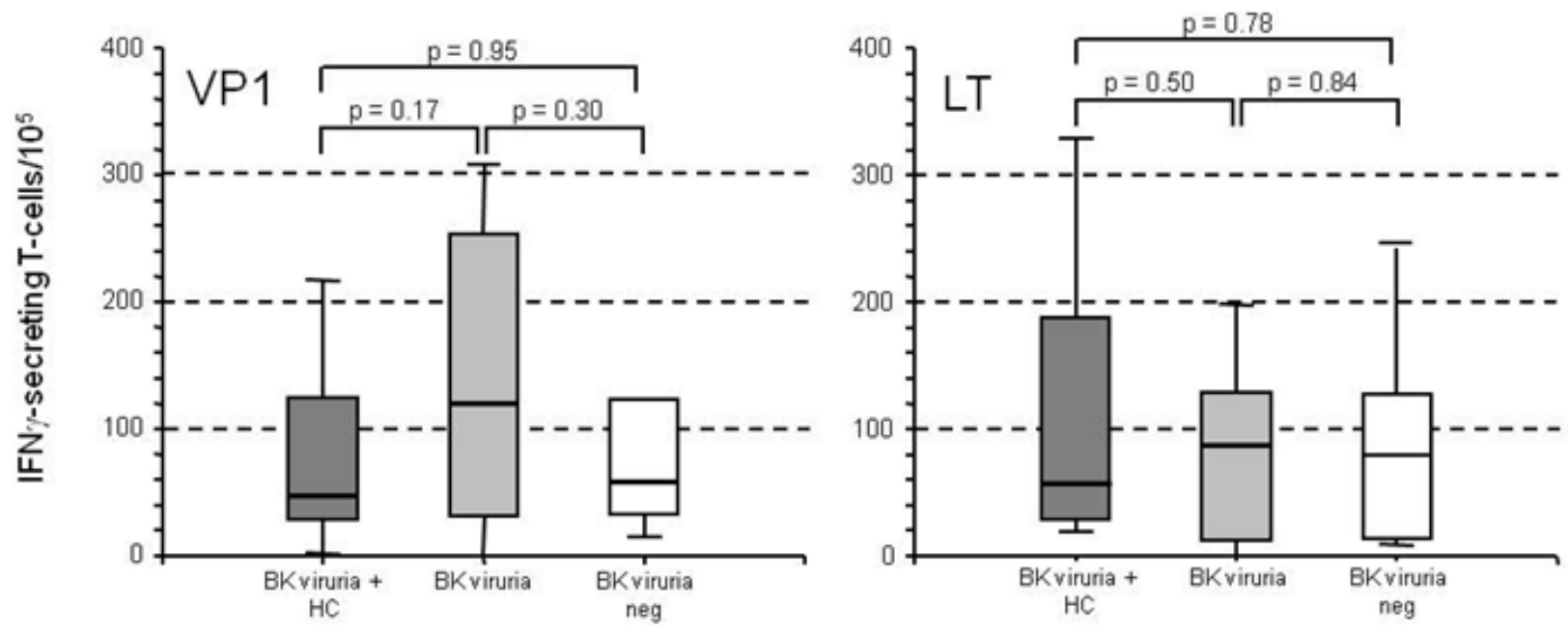

B
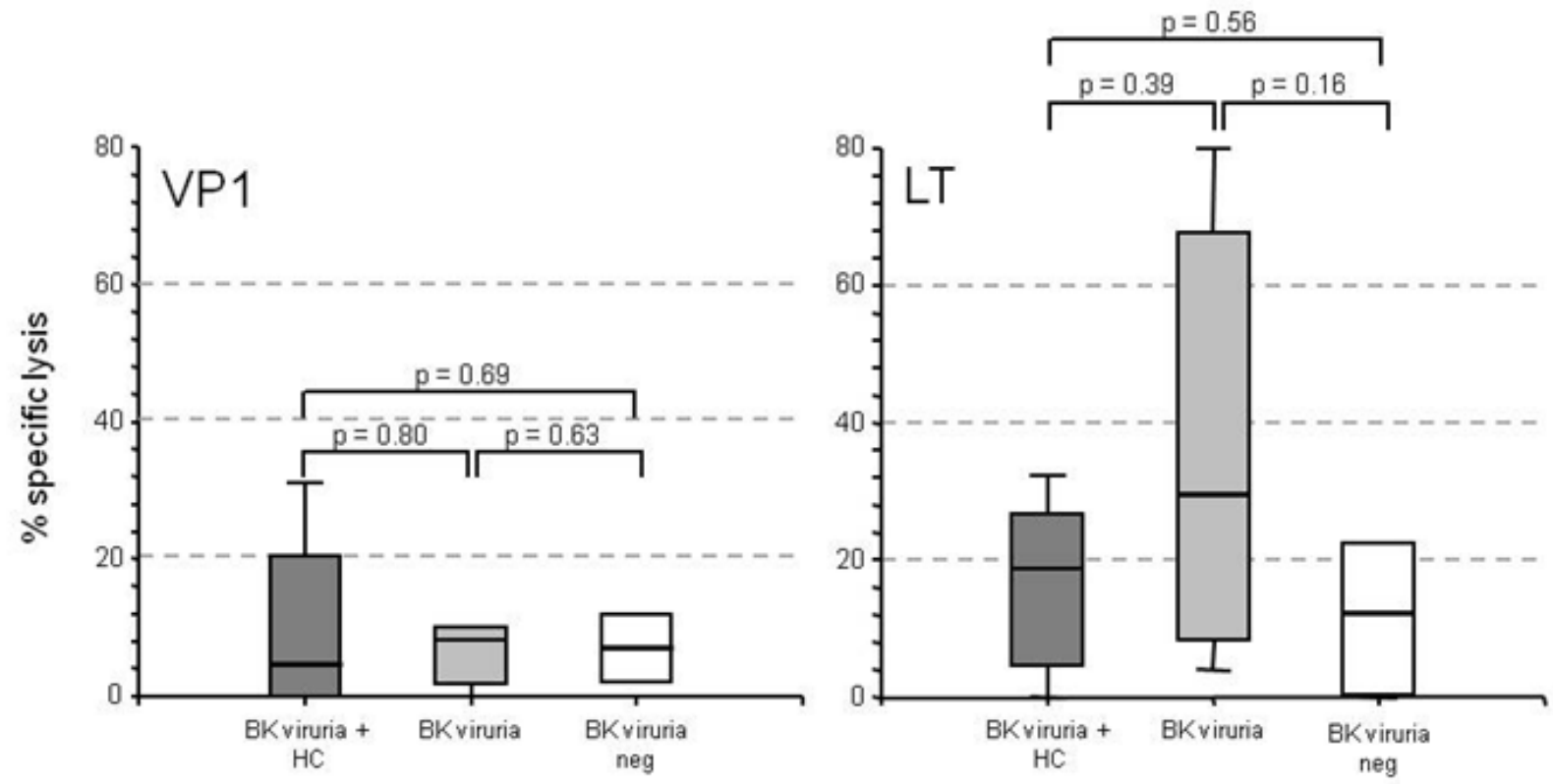

Figure 3: Cell-mediated responses to BKV in donors. A: BKV-specific IFN-y production after 10 days stimulation with VP1 and T peptides, was measured by ELISPOT assay, and reported as number of spots $/ 10^{5} \mathrm{PBMC}$, (median spots of triplicate experiments \pm SD). B: BKV specific cytotoxicity in donors, after 10 day stimulation with VP1 and T peptides. Cytotoxicity is represented as \% specific lysis at an effector to target ratio of 10:1 (mean of triplicate experiments \pm SD). As target, we used autologous PHA-blasts pulsed with VP1/T peptides; autologous mock-treated PHA-blastes were used as background.

All P values are reported. Evaluated groups: Group 1: donors whose recipients developed HC; Group 2: donors whose recipients showed BK viruria; Group 3 : donors whose recipients without $\mathrm{BK}$ viruria.

which are at risk of BK-associated interstitial nephritis. In this setting of patients, increased incidence of reactivation and clinical disease has been linked to the degree of immune compromise [29,30]. Furthermore, in kidney recipients, there is clear evidence suggesting that control of BK replication and BK-nephritis is correlated with development or reconstitution of BK-specific cellular immune responses [23,31]. PostHSCT pathogen surveillance is the results of both extent of donor antigen-specific mature T-cell transfer and ability of antigen-specific $\mathrm{T}$ cell regeneration from stem cell inoculum. With our study, we have evaluated only the former. Additional evidence will have to be collected on the role of BKV-specific cellular immunity reconstitution after HSCT on BKV infection and $\mathrm{HC}$ development that may allow to get further insight into HC pathogenesis.

In conclusion, although we cannot rule out that in some cases also immune reconstitution could play a role in the pathogenesis of $\mathrm{HC}$, our preliminary data suggest that $\mathrm{BKV}$-related $\mathrm{HC}$ may be related to low donor BKV-specific cytotoxic T cell transfer, perhaps coupled with impairment in $\mathrm{BKV}$-specific $\mathrm{T}$ cell expansion posttransplant. 
Citation: Basso S, Algeri M, Gurrado A, Cioni M, Guido I, et al. (2013) Role of Donor Virus-specific Immunity in the Onset of BKV-related Hemorrhagic Cystitis after Hemopoietic Stem Cell Transplantation. J Stem Cell Res Ther S6: 007. doi:10.4172/2157-7633.S6-007

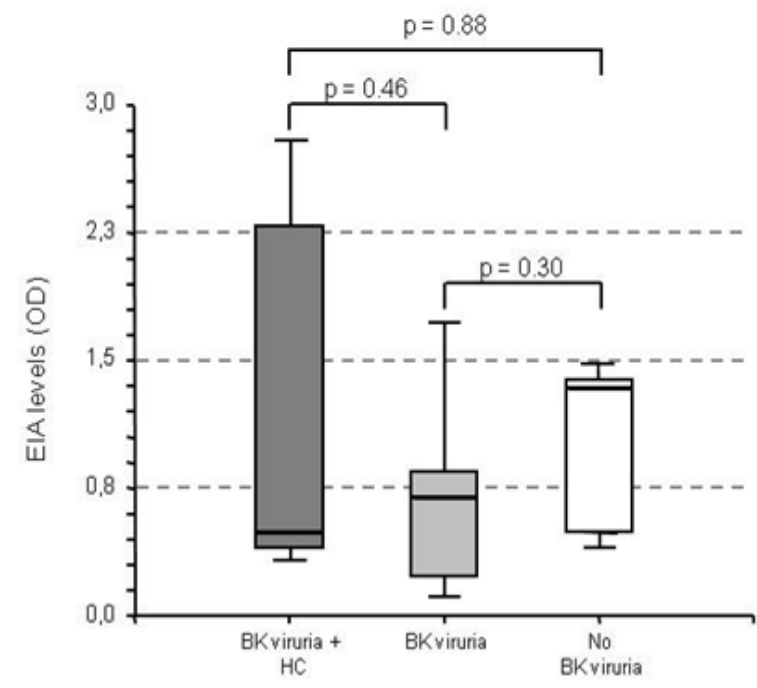

Figure 4: Levels of BKV-specific antibodies in the donor cohort. Data on donors' anti-BKV IgG are reported as median and quartiles. All $P$ values are reported. Evaluated groups: Group 1: donors whose recipients developed HC Group 2: donors whose recipients showed BK viruria; Group 3: donors whose recipients without $\mathrm{BK}$ viruria.

\section{Acknowledgements}

This study was supported by grants from the Ministry of Health, Ricerca Finalizzata (PC, MZ, FB); Fondazione IRCCS Policlinico S. Matteo Pavia, Ricerca Corrente (MZ, FB, PC); Associazione Italiana per la Ricerca sul Cancro (AIRC), Milan, Italy (PC, FB); Regione Lombardia, Progetto Trapianto (PC); grant from Fondazione La Nuova Speranza Onlus to PC; grant from Fondazione Cariplo (FB).

\section{Conflict of Interest}

The authors have no conflicts of interest to declare.

\section{References}

1. Sencer SF, Haake RJ, Weisdorf DJ (1993) Hemorrhagic cystitis after bone marrow transplantation. Transplantation 56: 875-879.

2. Santos GW, Tutchka PJ, Brookmeyer R, Saral R, Beschorner WE, et al. (1983) Marrow transplantation for acute non-lymphoocytic leukemia after treatment with busulfan and cyclophosphamide. N Engl J Med 309: 1347-1353.

3. Brugieres L, Hartman O, Travagli JP, Benhamou E, Pico JL, et al. (1989) Hemorrhagic cystitis after high-dose chemothepy and bone marrow transplantation in children with malignancies: incidence, clinical course and outcome. J Clin Oncol 7: 194-199.

4. Bedi A, Miller CB, Hanson JL, Goodman S, Ambinder RF, et al. (1995) Association of BK virus with failure of prophylaxis against hemorrhagic cystitis following bone marrow transplantation. J Clin Oncol 13: 1103-1109.

5. Leung AY, Mak R, Lie AK, Yuen KY, Cheng VC, et al. (2002) Clinicopathological features and risk factors of clinically overt haemorrhagic cystitis complicating bone marrow transplantion. Bone Marrow Transplant 29: 509-513.

6. Cesaro S, Facchin C, Tridello G, Messina C, Calore E, et al. (2008) A prospective study of BK-virus associated hemorrhagic cystitis in paediatric patients undergoing allogeneic stem cell transplantation. Bone Marrow Transplant 41: 363-370.

7. Arthur RR, Shah KV, Baust SJ, Santos GW, Saral R (1986) Association of BK viruria with hemorrhagic cystitis in recipients of bone marrow transplantation. $\mathrm{N}$ Engl J Med 315: 230-234

8. Hirsch HH, Steiger J (2003) Polyomavirus BK. Lancet Infect Dis 3: 611-623.

9. Hoffman JA, Shah AJ, Ross LA, Kapoor N (2001) Adenoviral infection and a prospective trial of cidofovir in pediatric hematopoietic stem cell transplantation. Biol Blood Marrow Transplant 7: 388-394.
10. Akiyama H, Kurosu T, Sakashita C, Inoue T, Mori Si, et al. (2001) Adenovirus is a key pathogen in hemorrhagic cystitis associated with bone marrow transplantation. Clin Infect Dis 32: 1325-1330.

11. Spach DH, Bauwens JE, Meyerson D, Mustafa MM, Bowden RA (1993) Cytomegalovirus induced hemorrhagic cystitis following bone marrow transplantation. Clin Infect Dis 16: 142-144.

12. Koskenvuo M, Dumoulin A, Lautenschlager I, Auvinen E, Mannonen L, et al. (2013) BK polyomavirus-associated hemorrhagic cystitis among pediatric allogeneic bone marrow transplant recipients: treatment response and evidence for nosocomial transmission. J Clin Virol 56: 77-81.

13. Reploeg MD, Storch GA, Clifford DB (2001) BK virus: a clinical review. Clin Infect Dis 33: 191-202.

14. Dropulic LK, Jones RJ (2008) Polyomavirus BK infection in blood and marrow transplant recipients. Bone Marrow Transplant 41: 11-18.

15. Azzi A, Cesaro S, Laszlo D, Ciappi S, De Santis R, et al. (1999) Human polyomavirus BK (BKV) load and hemorrhagic cystitis in bone marrow transplant recipients. J Clin Virol 14: 79-86.

16. Leung AY, Seun CK, Lie AK, Liang RH, Yuen KY, et al. (2001) Quantification of polyoma BK viruria in hemorrhagic cystitis complicating bone marrow transplantation. Blood 98: 1971-1978.

17. Erard V, Kim HW, Corey L, Limaye A, Huang ML, et al. (2005) BK DNA viral load in plasma: evidence for an association with hemorrhagic cystitis in allogeneic hematopoietic cell transplant recipients. Blood 106: 1130-1132.

18. Wong SY, Chan KH, Cheng VC, Yuen KY, Kwong YL, et al. (2007) Relationship of pretransplant polyoma $\mathrm{BK}$ virus serologic findings and $\mathrm{BK}$ viral reactivation after hematopoietic stem cell transplantation. Clin Infect Dis 44: 830-837.

19. Leung AY, Yuen KY, Kwong YL (2005) Polyoma BK virus and haemorrhagic cystitis in haematopoietic stem cell transplantation: a changing paradigm. Bone Marrow Transplant 36: 929-937.

20. Baldanti F, Fogazzi GB, Furione M, Saglimbeni L, Rovida F, et al. (2007) Quantification and identification of polyomavirus DNA in blood and urine of renal transplant recipients. Diagn Microbiol Infect Dis 57: 301-307.

21. Bodaghi S, Comoli P, Bösch R, Azzi A, Gosert R, et al. (2009) Antibody responses to recombinant polyomavirus BK Large T and VP1 proteins in young kidney transplant patients. J Clin Microbiol 47: 2577-2585.

22. Ginevri F, Azzi A, Hirsch HH, Basso S, Fontana I, et al. (2007) Prospective monitoring of polyomavirus $\mathrm{BK}$ replication and impact of pre-emptive intervention in pediatric kidney recipients. Am J Transplant 7: 2727.

23. Comoli P, Azzi A, Maccario R, Basso S, Botti G, et al. (2004) Polyomavirus BK-specific immunity after kidney transplantation in pediatric recipients. Transplantation 78: 1229-1232.

24. Binet I, Nickeleit V, Hirsch HH (2000) Polyomavirus infections in transplant recipients. Curr Opin Organ Transplant 5: 210-216.

25. Seber A, Shu XO, Defor T, Sencer S, Ramsay N (1999) Risk factors for severe hemorrhagic cystitis following BMT. Bone Marrow Transplant 23: 35-40.

26. Safdar A, Rubocki RJ, Horvath JA, Narayan KK, Waldron RL (2002) Fatal immune restoration disease in human immunodeficiency virus type 1-infected patients with progressive multifocal leukoencephalopathy: impact of antiretroviral therapy associated immune reconstitution. Clin Infect Dis 35: 1250-1257.

27. Cavazzana-Calvo M, André-Schmutz I, Dal Cortivo L, Neven B, Hacein-BeyAbina S, et al. (2009) Immune reconstitution after haematopoietic stem cell transplantation: obstacles and anticipated progress. Curr Opin Immunol 21: 544-548.

28. Silva Lde P, Patah PA, Saliba RM, Szewczyk NA, Gilman L, et al. (2010) Hemorrhagic cystitis after allogeneic hematopoietic stem cell transplants is the complex result of BK virus infection, preparative regimen intensity and donor type. Haematologica 95: 1183-1190.

29. Hirsch HH, Brennan DC, Drachenberg CB (2005) Polyomavirus-associated nephropathy in renal transplantation: interdisciplinary analyses and recommendations. Transplantation 79: 1277-1286.

30. Vasudev B, Hariharan S, Hussain SA, Zhu YR, Bresnahan BA, et al. (2005) BK virus nephritis: risk factors, timing, and outcome in renal transplant recipients. Kidney Int 68: 1834-1839.

31. Binggeli S, Egli A, Schaub S, Binet I, Mayr M, et al. (2007) Polyomavirus BK-specific cellular immune response to VP1 and large T-antigen in kidney transplant recipients. Am J Transplant 7: 1131-1139. 